\title{
Evacuated Window \\ Glazing Research and Development: A Progress Report
}

\author{
D. K. Benson \\ C. E. Tracy \\ G. J. Jorgensen
}
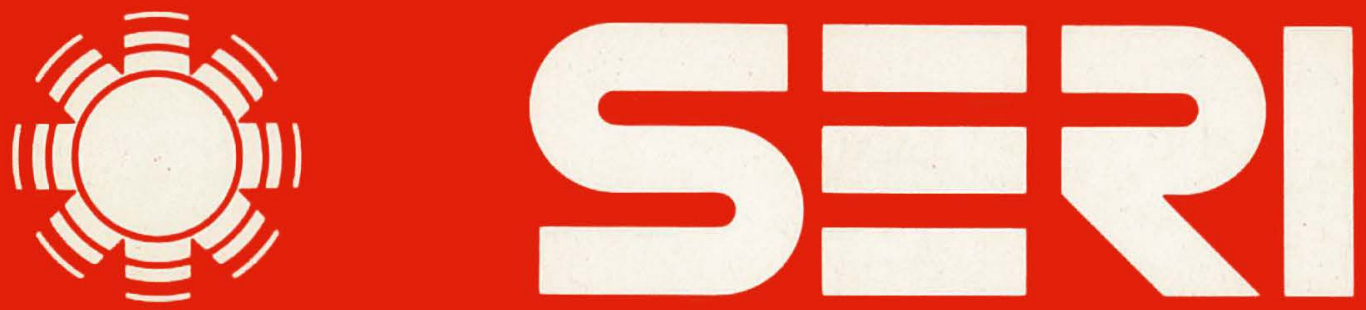

Solar Energy Research Institute A Division of Midwest Research Institute

1617 Cole Boulevard

Golden, Colorado 80401

Operated for the

\section{U.S. Department of Energy}

under Contract No. DE-AC02-83CH10093 


\section{NOTICE}

This report was prepared as an account of work sponsored by the United States Government. Neither the United States nor the United States Department of Energy, nor any of their employees, nor any of their contractors, subcontractors, or their employees, makes any warranty, express or implied, or assumes any legal liability or responsibility for the accuracy, completeness or usefulness of any information, apparatus, product or process disclosed, or represents that its use would not infringe privately owned rights. 


\title{
Evacuated Window Glazing Research and Development: A Progress Report
}

\author{
D. K. Benson \\ C. E. Tracy \\ G. J. Jorgensen
}

December 1984

Prepared under Task No. 4152.52

FTP No. 473

Solar Energy Research Institute

A Division of Midwest Research Institute

1617 Cole Boulevard

Golden, Colorado 80401

Prepared for the

U.S. Department of Energy

Contract No. DE-AC02-83CH10093 


\section{PREFACE}

This document summarizes progress during a nine-month period of an ongoing, exploratory research task. The objective of the research is to evaluate the technical feasibility of a highly insulating, evacuated glazing for windows and other building apertures. Research includes engineering design and analysis of the glazing structure, materials development for its components, and the development of fabrication processes that could be used in the practical, mass production of such a glazing system. The targeted design performance goals are $70 \%$ solar weighted transmittance with less than $0.5 \mathrm{~W} / \mathrm{m}^{2} \mathrm{~K}$ conductance (insulating $\mathrm{R}$ value greater than $12^{\circ} \mathrm{F} \mathrm{ft}^{2} \mathrm{~h} / \mathrm{Btu}$ ) with an acceptable view quality.

The energy costs of windows presently in U.S. buildings (both heat loss and unwanted heat gain) have been estimated to be 3.5 quadrillion Btu/yr $\left(3.5 \times 10^{18} \mathrm{~J} / \mathrm{yr}\right)$. The introduction of an improved glazing could greatly reduce this loss and improve building energy conservation. Other estimates based on computer simulations of the performance of passive solar heated buildings indicate that a highly insulating window could greatly extend the range of passive solar designs. For example, a window glazing with the targeted performance could be a net solar heat source in the northern United States, even on the north side of a building, where the diffuse and reflected solar radiation gain would more than offset the low thermal losses.

The authors gratefully acknowledge the assistance of J. Boswell and M. Ruth, who conducted the laser sealing experiments; D. Sallis (DAN-KA Products, Inc., Denver, Colo.), who conducted the NASTRAN computer simulation analyses; K. Masterson, who provided technical guidance; and C. Christensen, who assisted in the design analysis. This research was supported by the U.S. Department of Energy under contract No. DE-ACO2-83CH10093.

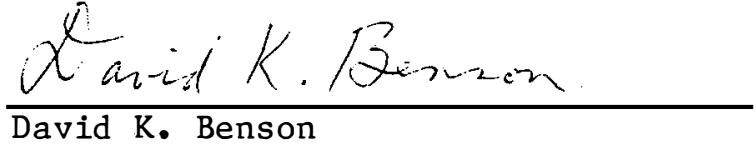

Approved for

SOLAR ENERGY RESEARCH INSTITUTE
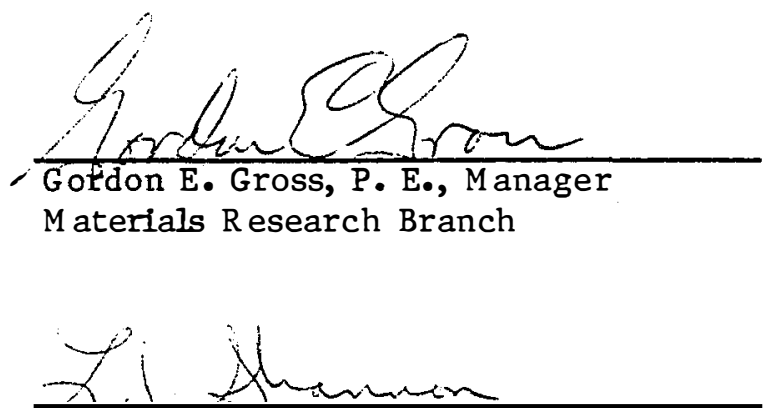

L. J. Shannon, Director Solar Heat Research Division 
TABLE OF CONTENTS

Page

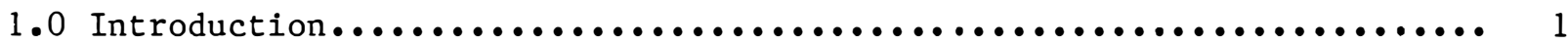

2.0 Design Analysis.................................... 3

3.0 Experimental Results................................. 7

4.0 Conclusions and Recommendations.......................... 10

5.0 References........................................ 11 


\section{LIST OF FIGURES}

$\underline{\text { Page }}$

1-1 Predicted Annual Energy Savings as a Function of Climate for

Different Kinds and Orientations of Window Glazing.............

1-2 Schematic Diagram of an Edge-Sealed, Al1-Glass Evacuated

Window Glazing.......................................

2-1 Thermal Network Model of Evacuated Window Glazing: (a) Insulated (Baffled) Perimeter; (b) Spherical Supports and Parallel Radiative Heat Path; (c) Detail of Spherical Support............. 3

2-2 The Effect of the Primary Coating Emittance on Thermal Performance of an Evacuated Window......................... 5

2-3 The Effect of an Insulated Perimeter Edge Baffle on the Thermal Performance on an Evacuated Window........................

2-4 The Effect of Diameter and Radial Spacing of Spherical Support on the Thermal Performance of an Evacuated Window.............. 6

3-1 The Effects of $\mathrm{CO}_{2}$ Laser Power and the Traverse Speed across the Glass Surface (Slew Rate) on the Type of Seal Obtained for Borosilicate Glass Plates ( $3 \mathrm{~mm}$ Thick) at $580^{\circ} \mathrm{C} \ldots \ldots \ldots \ldots \ldots$

\section{LIST OF TABLES}

2-1 Baseline Parameters of Thermal Analysis...................... 
SEPl嗦 
SECTION 1.0

\section{INTRODUCTION}

Apertures are important components in architectural designs, providing view, natural lighting, ventilation, and solar heating. However, existing building aperture systems have been estimated to cause as much as 3.5 quadrillion Btu/yr $\left(3.5 \times 10^{18} \mathrm{~J} / \mathrm{yr}\right)$ of energy loss in the United States [1]. Innovative use of existing designs or careful selection of apertures could save approximately

- $25 \%$ of building heating/cooling loads

- $50 \%$ of lighting loads

- $30 \%$ of peak electric demand [1].

The development of a significantly advanced aperture glazing system could provide even greater energy conservation.

In passive solar heated buildings where large areas of glazed aperture are used for solar gain, heat losses during periods of limited solar radiation can be a severe problem that limits passive solar usefulness to favorably oriented sites and moderate climates. However, estimates based on annual simulations of building energy performance indicate that a highly insulating window glazing could make passive solar designs more suitable for northern climates and less dependent upon favorable building orientation. Figure 1-1, for example, compares the predicted annual energy savings for standard, double glazed windows; an opaque, well insulated wall; state-of-the-art (multifilm) windows; and an evacuated $(R=12)$ window. The standard window has a solar weighted transmittance of $70 \%$ and an $R$ value of $2.2^{\circ} \mathrm{F} \mathrm{ft}^{2} \mathrm{~h} / \mathrm{Btu}\left(\mathrm{k}=2.6 \mathrm{~W} / \mathrm{m}^{2} \mathrm{~K}\right)$. These predictions suggest that an evacuated glazing could provide significant energy savings throughout the United States, even if used in north-facing windows.

The objective of our research has been to evaluate the technical feasibility of providing a more highly insulating window glazing by use of a vacuum gap and infrared reflective/low emissivity coatings. Figure 1-2 shows the design schematically, which is similar in principle to a vacuum Dewar and has similar insulating potential. Theoretical calculations indicate that a thermal conductance as low as $0.5 \mathrm{~W} / \mathrm{m}^{2} \mathrm{~K}\left(\mathrm{R}=12^{\circ} \mathrm{F} \mathrm{ft}^{2} \mathrm{~h} / \mathrm{Btu}\right)$ may be achieved with an optimized design.

For an evacuated window glazing to be effective, a high quality vacuum of $1.3 \times 10^{-3} \mathrm{~Pa}\left(10^{-5}\right.$ torr) must be established and maintained over periods of $\sim 30 \mathrm{yr}$. This requirement precludes the use of any polymeric materials for sealants. The seal we have chosen to evaluate first is an all-glass seal.

Vacuum maintenance will require the use of a reactive metal getter inside the sealed space to remove outgased and transmitted reactive gases. Helium permeation may require a countermeasure, depending in detail on the composition of the glass, the volume to surface area ratio of the evacuated space, the coatings used, and the average service temperature. Effective and practical barriers to helium diffusion are known and are used commercially in Dewars designed for use with liquid helium [3]. 


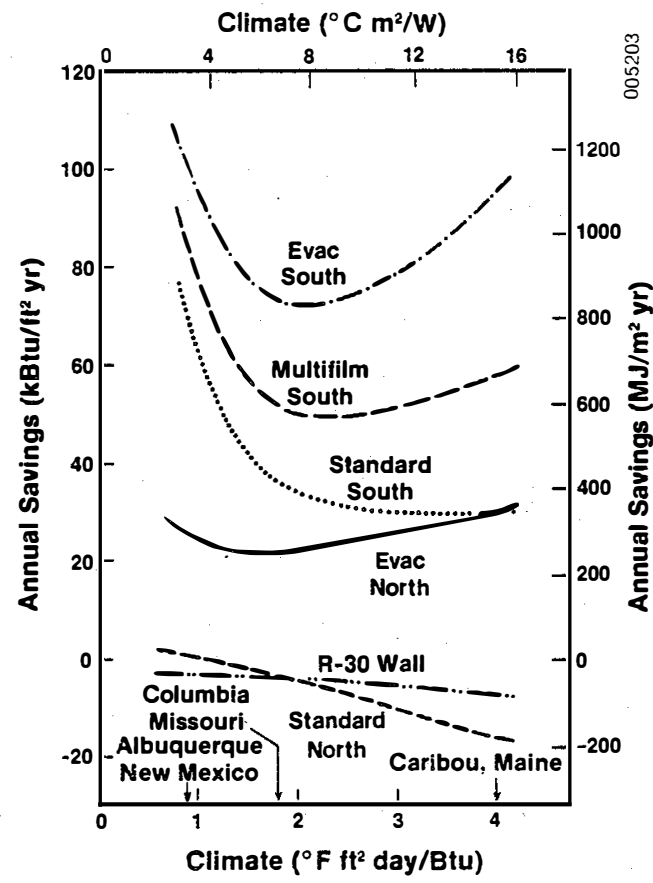

Figure 1-1. Predicted Annual Energy Savings as a Function of Climate for Different Kinds and Orientations of Window Glazings. (Ref. 2)
The integral, low emissivity coating is an essential and critical component in the evacuated window design. A large number of such coatings have been developed with high solar transmittances and low emissivities [4]. Most of these coatings may be economically applied by vacuum deposition in high throughput, mass production facilities. These coatings are likely to exhibit improved durability inside the evacuated space of a vacuum window, but it is not yet clear which ones may be able to withstand the temperatures required to seal them into the window.

Our initial efforts have focused predominantly on analyzing design options to arrive at an optimum in thermal and mechanical performance and on devising a fast and potentially economical sealing process. Work has only recently begun on the optimization of low emissivity coatings and development of a gettering system.

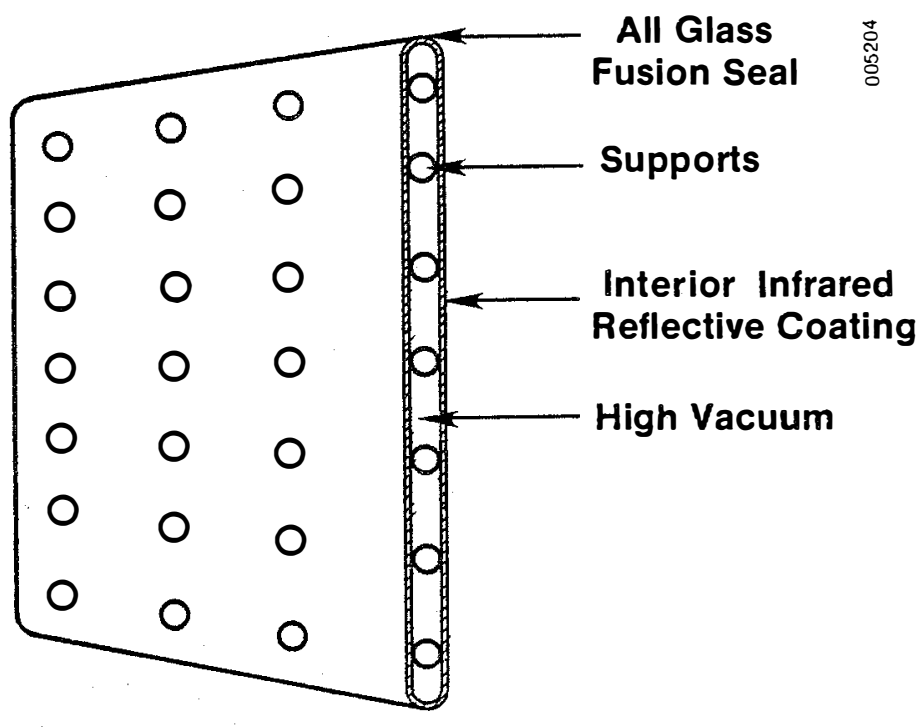

Figure 1-2. Schematic Diagram of an Edge-Sealed, Al1-Glass Evacuated Window Glazing 
SECTION 2.0

DESIGN ANALYSIS

The thermal performance of the evacuated glazing has been modeled as a thermal network and studied parametrically. Figure 2-1 shows the elements of the design and how they are represented by thermal resistances and nodal temperatures. Thermal conductance through the spherical support contacts was based on published, analytical results [5]. Radiative transfer across the vacuum space was calculated explicitly using a $\mathrm{T}^{4}$ temperature dependence, but assuming uniform temperatures over a window area of $1 \mathrm{~m}^{2}$.

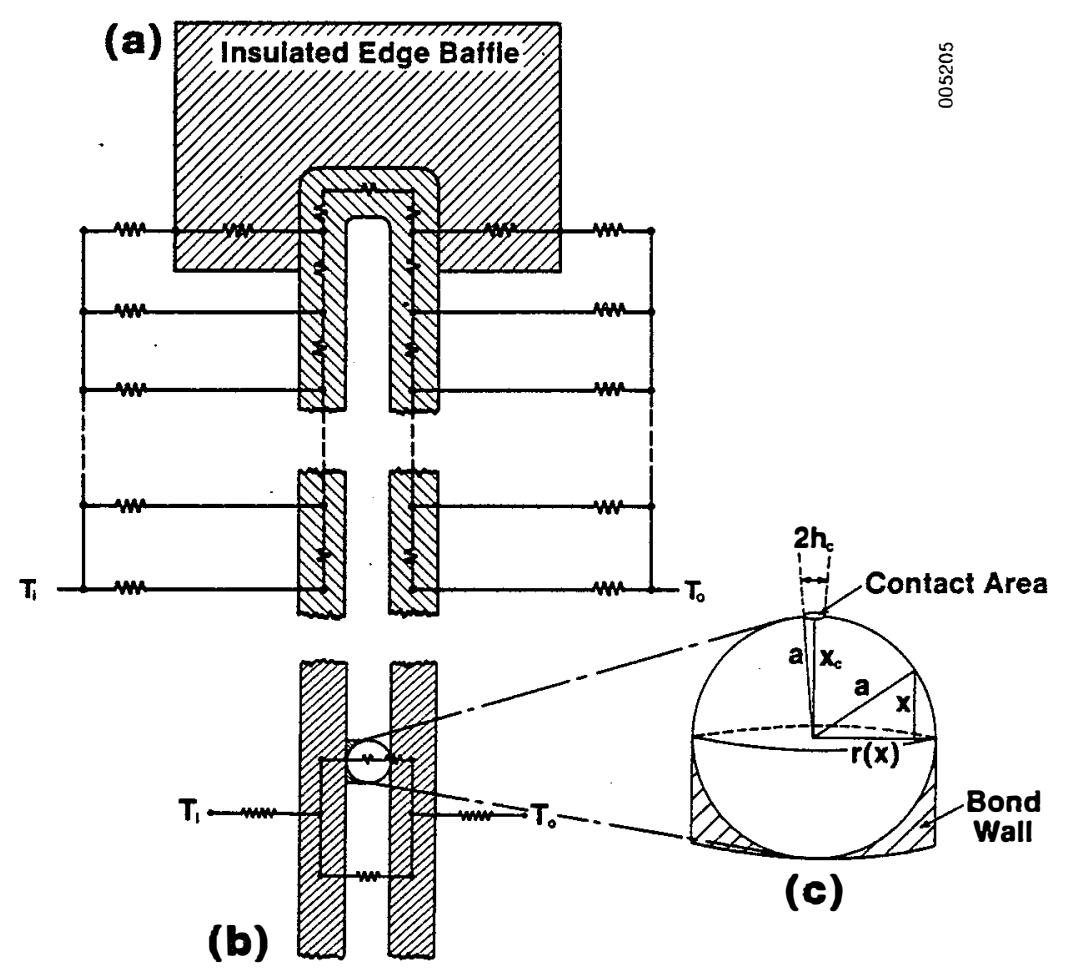

Figure 2-1. Thermal Network Model of an Evacuated Window Glazing: (a) Insulated (Baffled) Perimeter; (b) Spherical Supports and Parallel Radiative Beat Path; (c) Detail of Spherical Support

*This assumption tends to exaggerate the conduction heat loss through the spherical supports. 
The thermal conduction through the edge seals around the window perimeter is excessive unless the effective thermal path length is increased by the use of insulating edge baffles as shown in Figure 2-1(a). Figures 2-2 through 2-4 summarize some of the most significant parametric analyses. The starred point in each figure is a design reference case with parameters defined in Table 2-1.

Figure 2-2 shows the effect of coating emittance on thermal performance. A low emittance coating on one of the glass surfaces is essential, but only a marginal additional benefit is obtained from using low emittance coatings on both inner surfaces. This is because the radiative heat loss is adequately reduced by a single low emittance coating, and the conductive heat loss mechanism dominates once the radiative loss is reduced. Figure 2-3 shows the benefit of the insulating, perimeter edge baffle. Figure 2-4 shows the effect of the diameter and spacing of the supporting spheres (in a regular, square grid pattern) on thermal performance.

A finite element computer code, NASTRAN [6], is used to predict the mechanical stresses and thermal performance in selected design cases. Preliminary results indicate that even in a 90-mph wind, the base-case design window would

Table 2-1. Baseline Parameters of Thermal Analysis

\begin{tabular}{ll}
\hline $\mathrm{T}_{\mathrm{a}}$ - Ambient outside temperature & $-20^{\circ} \mathrm{C}\left(-4^{\circ} \mathrm{F}\right)^{\mathrm{b}}$ \\
$\mathrm{T}_{\mathrm{i}}$ - Inside temperature & $20^{\circ} \mathrm{C}\left(68^{\circ} \mathrm{F}\right)$ \\
$\mathrm{d}-$ Diameter of spacers & $3 \mathrm{~mm}(\sim 1 / 8 \mathrm{in} \bullet)$ \\
$\mathrm{s}-$ Spacing of spheres & $50 \mathrm{~mm}(\sim 2 \mathrm{in})$ \\
$\delta \mathrm{e}-$ Edge thickness & $3 \mathrm{~mm}(\sim 1 / 8 \mathrm{in} \bullet)$ \\
$\delta \mathrm{g}-$ Glazing thickness & $3 \mathrm{~mm}(\sim 1 / 8 \mathrm{in} \bullet)$ \\
$\varepsilon_{1}-$ Glass emittance & 0.84 \\
$\varepsilon_{2}-$ Infrared reflector emittance & 0.05 \\
$\varepsilon_{3}-$ Glass emittance & 0.84 \\
$\varepsilon_{4}-$ Glass emittance & 0.84 \\
$\mathrm{~A}-$ Glazing area & $1 \mathrm{~m}\left(\sim 11 \mathrm{ft}^{2}\right)$ \\
$\mathrm{v}-$ Wind speed & $6.7 \mathrm{~m} / \mathrm{s}(15 \mathrm{mph})$ \\
\hline
\end{tabular}

${ }^{a}$ Subscripts refer to glass surfaces numbered from the building interior.

$b_{\text {The thermal }}$ resistance of the evacuated glazing is nearly independent of temperature difference across the glazing. Only the radiative heat transfer mechanism is sensitive to the temperature difference. Increasing the temperature difference to $60^{\circ} \mathrm{C}\left(-40^{\circ} \mathrm{C}\right.$ outside, $+20^{\circ} \mathrm{C}$ inside; $\left.-40^{\circ} \mathrm{F},+68^{\circ} \mathrm{F}\right)$ causes only a $4 \%$ decrease in calculated R-value. 


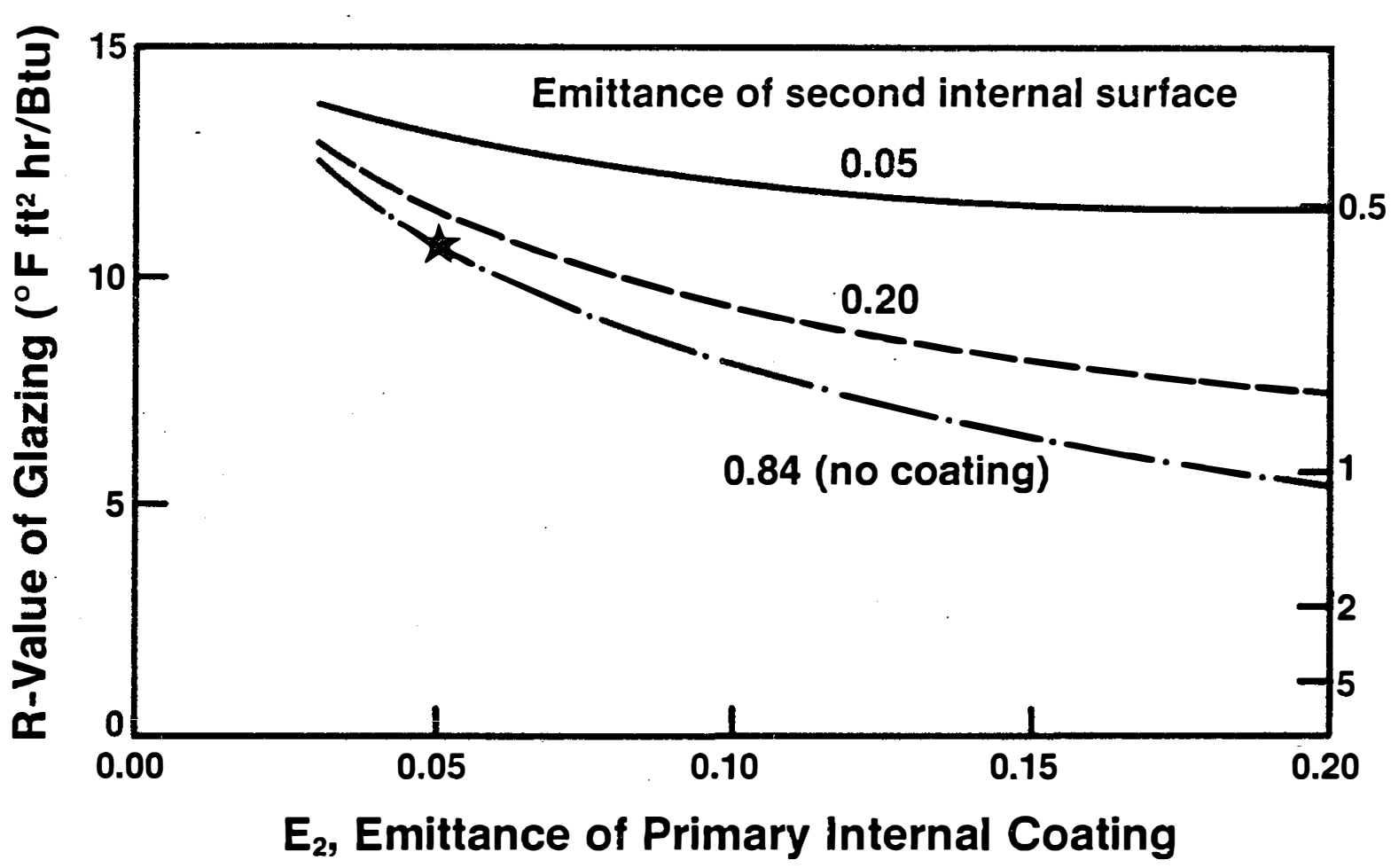

Figure 2-2. The Effect of the Primary Coating Emittance on the Thermal Performance of an Evacuated Window

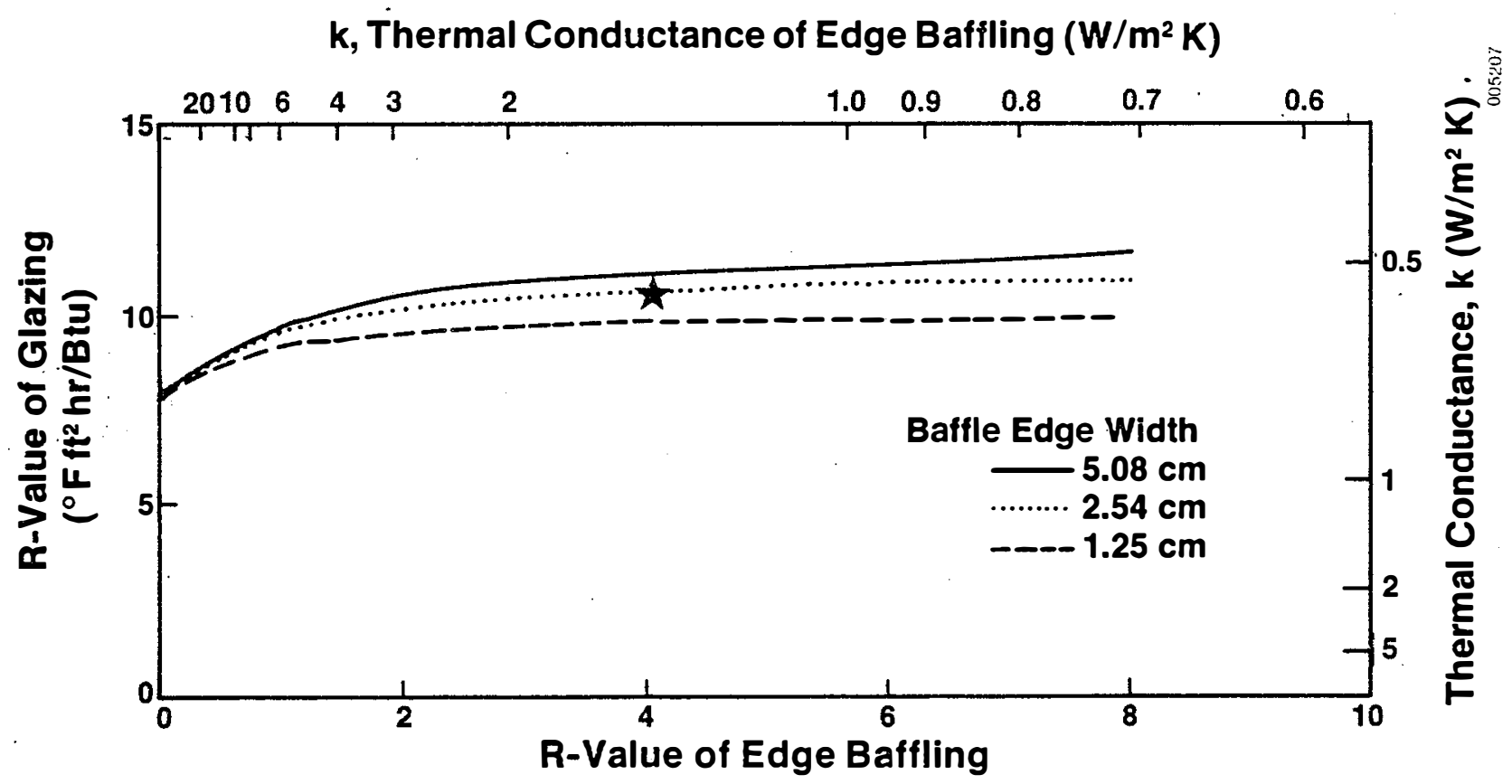

Figure 2-3. The Effect of an Insulated Perimeter Edge Baffle on the Thermal Performance of an Evacuated Window 


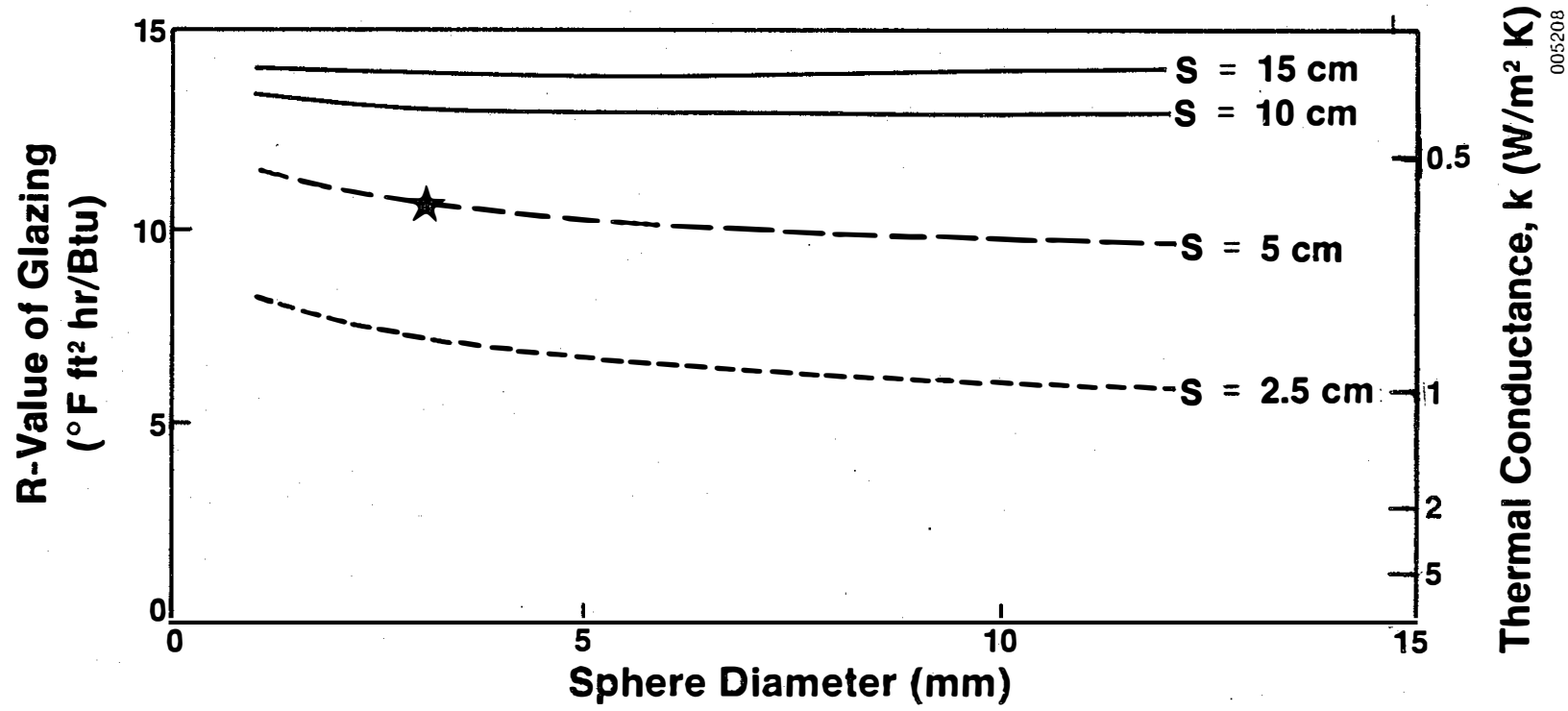

Figure 2-4. The Effect of Diameter and Radial Spacing of Spherical Support on the Thermal Performance of an Evacuated Window

experience a maximum tensile stress near the edge, midway between corners, of 1971 psi. Under a typical thermal gradient of $+20^{\circ} \mathrm{C}$ indoors and $-20^{\circ} \mathrm{C}$ outdoors $\left(68^{\circ} \mathrm{F}\right.$ to $\left.-4^{\circ} \mathrm{F}\right)$ the maximum thermally induced tensile stress occurs in the corners and is critically dependent on the compliance of the window support. In the worst case (rigid supports allowing no out-of-plane deflection at the perimeter), this tensile stress is $15.6 \mathrm{MPa}(2263 \mathrm{psi})$. These stress levels are acceptably low, but will be further reduced by design improvements.*

*The very conservative design stress level conventionally recommended by the glass industry is $6.9 \mathrm{MPa}$ (1000 psi). 
SECTION 3.0

\section{EXPERIMENTAL RESULTS}

A 400-W CW $\mathrm{CO}_{2}$ laser* has been used to evaluate laser sealing as an option for fabricating an evacuated window. The potential advantages of laser sealing are (1) it is a clean and efficient means of delivering localized power to the seal area; (2) the laser beam is easily directed and easily introduced into a vacuum furnace where the evacuated window could be sealed after receiving its low emissivity coating; (3) the $10.6-\mu \mathrm{m}$ wavelength laser radiation is strongly absorbed by the glass matrix; and (4) laser sealing is a potentially fast sealing method (e.g., by using more powerful industrial lasers).

Eliminating thermal shock fracture requires preheating the glass to above its annealing temperature before laser sealing. A borosilicate glass was used to improve further the thermal shock resistance. The spherical supports were bonded in place with sodium silicate during test specimen fabrication experiments. However, spot-welding the spheres in place using the laser has been successful; with refinement this technique may become the preferred means of attachment in production.

The economics of laser sealing depend on its speed. A preliminary analysis suggested that the production costs would vary inversely with the sealing rate [7]. Experiments with a research scale laser were extrapolated to provide a rough estimate of the possible sealing speed with an industrial size laser. Figure 3-1 shows results of a series of experiments used to define the critical sealing speed parametrically.

In these experiments $3-\mathrm{mm}-t h i c k$ flat sheets of borosilicate glass were welded at $580^{\circ} \mathrm{C}$ with a sharply focused $\left(25-\mathrm{cm}\right.$ focal length lens) $\mathrm{CO}_{2}$ laser beam in the TEM ${ }_{\text {Oo }}$ mode (a single, Gaussian-shaped power distribution) perpendicular to the glass surface. The speed of sealing and the power of the laser were varied systematically. The quality of the seal was judged by visual inspection and qualitative mechanical testing.

The maximum sealing rate $R$ in centimeters per second under these conditions can be expressed as

$$
R=\frac{P-237}{2716} \text {, }
$$

where $\mathrm{P}$ is the laser power in watts. If this expression is extrapolated to $5 \mathrm{~kW}$, a typical power level for an industrial laser, the sealing rate could be as high as $1.75 \mathrm{~cm} / \mathrm{s}$. At this sealing rate, production costs could be expected to fall below $\$ 35 / \mathrm{m}^{2}\left(\$ 3.25 / \mathrm{ft}^{2}\right)$, much less than the previously predicted $\$ 108 / \mathrm{m}^{2}\left(\$ 10 / \mathrm{ft}^{2}\right)$ value of the evacuated glazing [7]. Even higher sealing rates may be possible with higher power lasers. Rates in excess of $1 \mathrm{~m} / \mathrm{s}$ have been demonstrated in laser welding of metals [8].

*Coherent Everlase Mode1 325. 


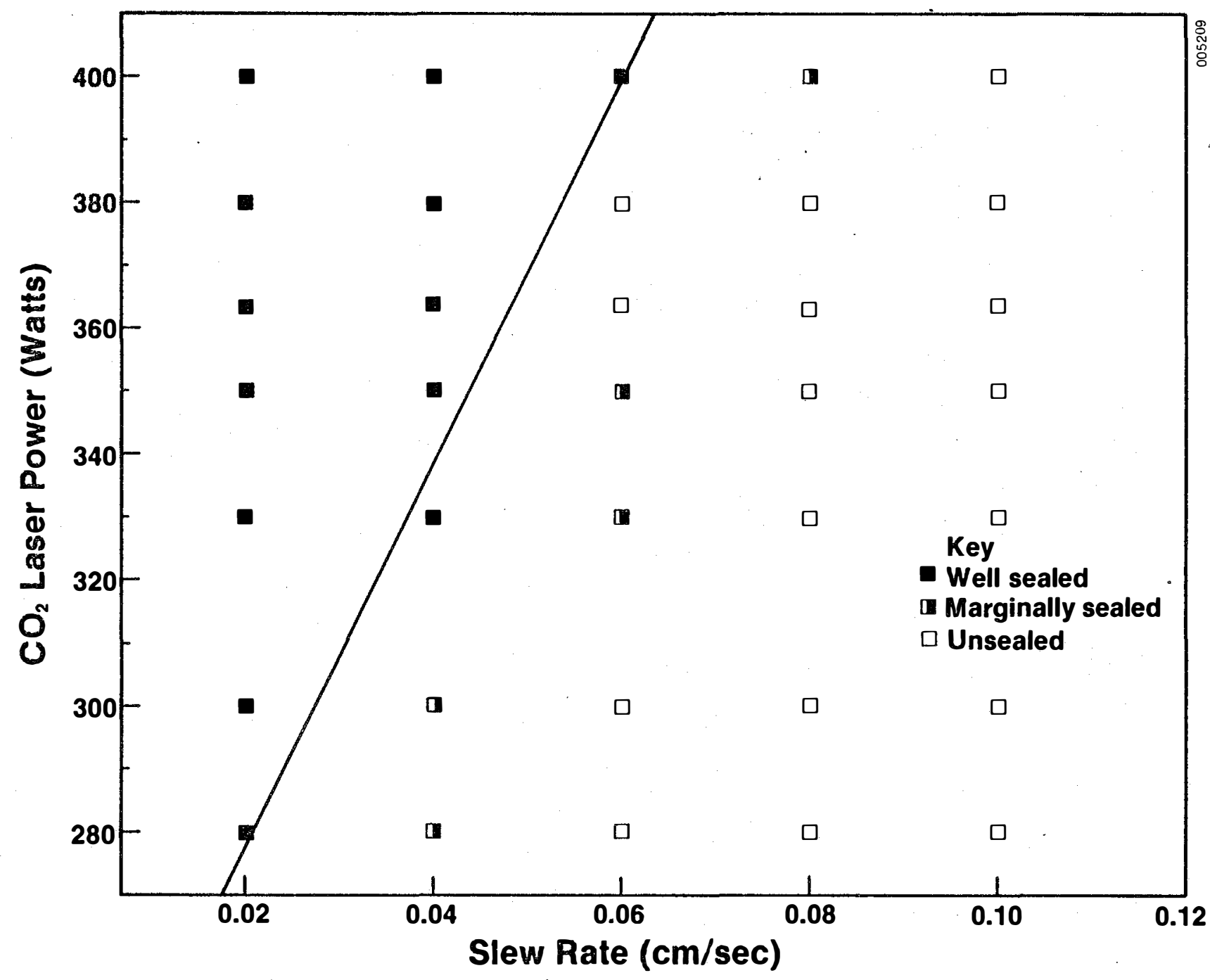

Figure 3-1. The Effects of $\mathrm{CO}_{2}$ Laser Power and the Traverse Speed Across the Glass Surface (Slew Rate) on the Type of Seal Obtained for Borosilicate Glass Plates (3 mm Thick) at $580^{\circ} \mathrm{C}$ 
Complete, perimeter-sealed test specimens $25 \mathrm{~cm} \times 25 \mathrm{~cm}$ square have been fabricated with regularly spaced spherical supports and an integral low emissivity coating of fluorine doped tin oxide $\left(\mathrm{SnO}_{2}: \mathrm{F}\right)$. These units were fabricated in air; a partial vacuum was retained when the air inside cooled from $580^{\circ} \mathrm{C}$ to room temperature. Fabricating evacuated test units awaits availability of a vacuum furnace at SERI's laser processing laboratory.

As indicated in Figure 2-4, using smaller diameter spherical supports in the vacuum space improves the thermal resistance of the evacuated window. We have not yet calculated the improvement to be expected with diameters less than $1 \mathrm{~mm}$, but we have fabricated test specimens with such small supports. The smaller support diameter improves the visibility through the evacuated glazing. Laser-sealed test specimens have been fabricated with 0.5-mm-diameter and $0.3-\mathrm{mm}-$ diameter $(0.02-$ and $0.012-i n$.$) spacers. At these small diameters,$ the spacers are almost invisible. However, irregularities in the flatness of the Pyrex glass sheets allow them to touch when the gap is only $0.3 \mathrm{~mm}$. A flatter, borosilicate glass sheet, which is newly marketed in the United States by Schott Glaswerke, West Germany, will be evaluated when samples become available.

The preliminary test specimens fabricated to date have been laser sealed in air at $580^{\circ} \mathrm{C}$. The only readily available, low emissivity coating that withstands these conditions is semiconductor tin oxide. Commercial, fluorine doped tin oxide coating from Pittsburgh Plate Glass ("Nesa glass") was used in these preliminary experiments. The emissivity of this coating has been measured before $(0.188)$ and after $(0.223)$ heating to $580^{\circ} \mathrm{C}$ in air. Reference to Figure 2-2 clearly shows that such a coating would not be adequate. A much lower emissivity is required.

When the window glazing is fabricated in vacuum, other coatings can be considered. Semiconductor indium oxide, for example, exhibits optimum emittance of 0.08 in air. The effect of high-temperature, vacuum exposure on such coatings was tested. One commercially available tin-doped, indium oxide film (Pittsburgh Plate Glass "Nesatron glass") exhibited low emissivity before $(0.096)$ and after $(0.108)$ heating above $500^{\circ} \mathrm{C}$ in vacuum. Other candidate low emissivity coatings will also be evaluated. 


\title{
SECTION 4.0
}

\section{CONCLUSIONS AND RECOMMENDATIONS}

\begin{abstract}
We have made a preliminary evaluation of the design and fabrication of a sealed and evacuated, insulating window glazing. An all-glass, edge-sealed window with integral, spherical supports and one low emissivity coating appears to have the potential for good performance characteristics. Such a window may provide a thermal conductance less than $0.5 \mathrm{~W} / \mathrm{m}^{2} \mathrm{~K}$ $\left(\mathrm{R}<12^{\circ} \mathrm{F} \mathrm{ft}^{2} \mathrm{~h} / \mathrm{Btu}\right)$ in a compact ( $<7 \mathrm{~mm}$ thick) and lightweight $\left(\sim 14 \mathrm{~kg} / \mathrm{m}^{2}\right.$; $\left.2.9 \mathrm{lb} / \mathrm{ft}^{2}\right)$ structure. Laser edge sealing of such a structure has been demonstrated (in air). Sealing speeds in excess of $1 \mathrm{~cm} / \mathrm{s}$ can be predicted for industrial-scale lasers ( $\sim 3 \mathrm{~kW}$ CW power) from experiments with a $400-\mathrm{W} \mathrm{CW} \mathrm{CO}_{2}$ laser.

We recommend additional research and development to optimize and test the basic design concept. In particular, lower emissivity coatings that can withstand a $580^{\circ} \mathrm{C}$ process temperature in vacuum are needed; a reactive gettering system must be developed; helium permeation through the glass must be carefully evaluated as a threat to vacuum integrity; and fracture resistance of the structure must be evaluated, particularly in the vicinity of the spherical supports.
\end{abstract}

Using a vacuum furnace in the fabrication of test specimens is essential to the success of this research and development effort. The authors strongly recommend allocation of capital equipment funds to this task for that purpose. 
SECTION 5.0

\section{REFERENCES}

1. Selkowitz, S., "Aperture Materials Program, Semi-Annual Program/ Management Review," Sept. 11, 1984, Washington, D.C.

2. Neeper, D. A., and R. D. McFarland, Some Potential Benefits of Fundamental Research for the Passive Solar Heating and Cooling of Buildings, Report No. LA-9425, Los Alamos, N. Mex•: Los Alamos National Laboratory, 1981.

3. Bryant, P. G., and C. M. Gosselin, "Method of Treating Glass to Reduce Helium Permeation," U.S. Patent No. 3,395,997, 1968.

4. Chopra, K. L., et al., "Transparent Conductors - A Status Review," Thin Solid Films, Vol. 102, 1983, pp. 1-46.

5. Cooper, M. G., et al., "Thermal Contact Conductance," Int. J. Heat and Mass Transfer, Vo1. 12, 1969, pp. 279-300.

6. Schaeffer, H. G., "Static and Normal Mode Analysis: A Study of Computerized Technology," MSC/NASTRAN Primer, Mount Vernon, N.H.: Schaeffer Analysis, Inc., 1979.

7. Benson, D. K., et al., Evacuated Glazings for Energy Efficient Buildings, SERI/PR-255-2421, Draft, Golden, C0: Solar Energy Research Institute, August 1984.

8. Private communication with Scott White, Spectra-Physics, San Jose, CA, Oct. 23, 1984 . 